Association for Information Systems AIS Electronic Library (AISeL)

Research Papers

ECIS 2019 Proceedings

5-15-2019

\title{
MOVING BEYOND SHOWCASING. THE FIVE FACES OF LEADERSHIP IN SMART CITY TRANSFORMATION
}

Jocelyn Cranefield

Victoria University of Wellington, jocelyn.cranefield@vuw.ac.nz

Jan Pries-Heje

Roskilde University, janph@ruc.dk

Follow this and additional works at: https://aisel.aisnet.org/ecis2019_rp

\section{Recommended Citation}

Cranefield, Jocelyn and Pries-Heje, Jan, (2019). "MOVING BEYOND SHOWCASING. THE FIVE FACES OF LEADERSHIP IN SMART CITY TRANSFORMATION". In Proceedings of the 27th European Conference on Information Systems (ECIS), Stockholm \& Uppsala, Sweden, June 8-14, 2019. ISBN 978-1-7336325-0-8 Research Papers.

https://aisel.aisnet.org/ecis2019_rp/113

This material is brought to you by the ECIS 2019 Proceedings at AIS Electronic Library (AISeL). It has been accepted for inclusion in Research Papers by an authorized administrator of AIS Electronic Library (AISeL). For more information, please contact elibrary@aisnet.org. 


\title{
MOVING BEYOND SHOWCASING: THE FIVE FACES OF LEADERSHIP IN SMART CITY TRANSFORMATION
}

\author{
Research paper \\ Jocelyn Cranefield, Victoria University of Wellington, New Zealand \\ jocelyn.cranefield@vuw.ac.nz \\ Jan Pries-Heje, Roskilde University, Denmark \\ janph@ruc.dk
}

\begin{abstract}
The smart city concept is used as tool by local and municipal governments to deliver benefits relating to people, government, economy, mobility, environment and living. By embedding technologies and the internet of things in the city's infrastructure, smart cities aim to generate insights that drive local improvements and accrue to a global level. The smart city is also viewed as a transformative lever for government. As cities move beyond smart city pilot showcasing projects, they face the challenge of embedding smart city initiatives in business-as-usual. Despite ambitious goals and high stakes, little is known about the work that leaders perform in undertaking this transformation. This study explored the leadership practice of smart city leaders in Denmark, Holland, USA, Australia and New Zealand. We focus on how leaders drive transformation from showcasing to becoming a sustainable smart city, and the challenges faced. As result we present a framework of six barriers to overcome and five enacted leadership roles to transform the city of today to a future sustainable smart city. We use institutional logics as a lens to discuss and explain the challenges faced by city leaders and their critical role as innovation agents and boundary spanners in smart city transformation.
\end{abstract}

Keywords: Smart city, transformation, leadership, sustainability, institutional logics 


\section{Introduction}

From Barcelona to Bubaneswar, and Reykjavik to Rio de Janeiro, an increasing number of cities around the world are embarking on the quest to become a smart city. Some 150+ smart city cases are recorded (Anthopoulos et al., 2019), over a thousand smart city pilots are in progress (Lin 2018), and multiple tracts of land have been dedicated to build new smart cities from scratch. This smart-rush has created a burgeoning multi-billion-dollar industry of consultants and suppliers of technology, services and infrastructure. In 2017, the global smart cities market was valued at US $\$ 529.55$. It is forecast to reach US \$1944.67 billion by the end of 2023 (Reuters 2018). Further, the smart city movement has taken on a competitive dimension, with frequent media reports of which cities are leading or following, based on global rankings.

As an innovation, the smart city has arisen both from a technology-push force and from innovative strategies drafted by city governments worldwide (Anthopoulos 2017). Whether delivered via public organisations directly, or through public-private partnerships or project coalitions, smart city initiatives are typically funded and guided by local governments and municipalities (Anthopoulos and Reddick 2016b). From a government perspective, smart cities are seen as a means to help improve the efficiency and democracy of public service delivery (Anthopoulos and Reddick 2016b, 100). Specifically, by embedding technology in the city's infrastructure, smart cities aim to generate data and insights that can be used to help improve urban life across the dimensions of people, government, economy, mobility, environment and living (Giffinger et al., 2007). At a higher level, the smart city phenomenon is seen as a means to help solve the "tangled and wicked problems" of urbanisation that span social, political and organisational realms (Nam and Pardo 2011, 185). Smart city initiatives are also seen as transformative in relationship to government administration. In a review of the relationship between the smart city and smart government, Anthopolous and Reddick (2016a) conclude that smart government is needed to lead smart city developments, and that the smart city is an area for the practice of smart government (p.354). In combination, these smart city goals are transformative.

The smart city movement is associated with a sense of growing gravity and urgency, owing to the fact that two-thirds of the world's population (an estimated 6.5 billion people) are expected to be living in cities by 2050 (United Nations Development Programme 2017). For governments, particularly for those who are leading the smart city transformation, the stakes are high. It is seen as essential to move beyond technological considerations and better understand the management and policy issues that are involved in the smart city (Nam and Pardo, 2011). Despite a substantial raft of publications, the smart city is still an embryonic area of study (Anthopoulos et al. 2019). In particular, little is known about the practical experience of those charged with leading smart city transformation, and the issues faced by these leaders as cities begin to move beyond show-casing of quick wins from pilot projects towards embedding the smart city in business as usual. Our study aimed to address this gap. Based on exploratory interviews with seven individuals, the study sought to understand, What barriers are faced by leaders of smart city transformation? and How do smart city leaders foster sustainable change? In the remainder of this paper, we review the literature of relevance, then outline the study method, before reporting on the findings. In the discussion we draw on Institutional Logics theory to consider the significance of the findings.

\section{$2 \quad$ Literature Review}

The smart city concept was originally focused around the diffusion of ICT in the city, then later became more inclusive of people and community needs (Albino et al. 2015). Nonetheless, there is considerable variation in the ways in which the term "smart city" has been used by cities in their approaches to innovation, development and branding, and in how the concept is used in academic studies. Scholars are in agreement there is no single agreed definition of a smart city (Nam and Pardo 2011; Albino et al. 2015). Although the adjective smart "clearly implies some kind of positive urbanbased technological innovation and change via ICTs", it has also been used in relationship to egovernance, communities and social learning, as well as addressing issues of urban growth and social 
and environmental sustainability (Hollands 2008, 303). In some cases, the term smart is employed in an instrumental way, to imply the use of smart means, while in others smartness is seen as normative, an outcome to be aimed for (Höjer and Wangel 2015). Such interpretive flexibility may be helpful in terms of supporting city-level differentiation, but it is problematic for generalisability. For example, Anthopolous et al. (2019) have highlighted how the diverse smart city conceptualization has had a roll-on impact on benchmarking and evaluation tools. Perhaps unsurprisingly, the term smart city has been described as a buzzword (Höjer and Wangel 2015), a vague or fuzzy concept (Bibri and Krogstie 2017; Nam and Pardo 2011; Albino et al. 2015) and an urban labelling phenomenon with a selfcongratulatory tendency (Hollands 2008).

Nonetheless, the emergence of the smart city as a global phenomenon is reflected in significant research interest. Anthopolous and Reddick (2016b) describe the smart city as being "a radically emerging" and inter-disciplinary domain since its initial appearance in 1997 (p.112). A search on Google Scholar in October 2018 using the term "smart city" (excluding analogues) returned 65.500 results, with only 1.630 articles predating 2010, and 10.500 results for 2018 to date. Despite these impressive statistics, the smart city is seen as an embryonic area of study (Anthopoulos et al. 2019). Recent studies have focused on taking stock of the literature to identify common conceptual ground and assist in articulating the future research agenda (Anthopoulos et al. 2019; Albino et al. 2015; Bibri and Krogstie 2017; Brauer et al. 2015; Chourabi et al. 2012; Cocchia 2014; Nam and Pardo 2011). A common element of the smart city development approach remains "the idea that ICT is, and will be for many years to come, central to urban operations, functions, services, and designs" (Bibri and Krogstie 2017, 191). Associated with this theme is an emphasis on the use of the Internet of Things (IoT) to generate data that can in future be analysed to improve efficiency and guide decision-making (Khan et al. 2015). For example, cameras and sensors may be integrated into city infrastructure to gather diverse data, while streetlight connectivity may become the basis for a WAN. Data generated may be aggregated and analysed in combination with other data, such as that held by the city and agencies such as police, fire and emergency departments. The smart city is therefore seen by some as becoming an application for future big data analytics (Khan et al. 2015), to help guide and/or automate decisionmaking, increase efficiency and achieve goals. As Gartner writer Kasey Panetta puts it, "Most citizens might view a streetlamp as just a streetlamp, but to a city planner in a smart city, a light post is an opportunity to build a framework for optimizing city operations such as environment, transportation, and safety and security" (Panetta 2017 ). Potential applications of city data include transport and CO2 emission, energy efficiency, security and emergency services, waste and water management, city management, economic development, public health, and informed public participation (Khan et al. 2015).

Researchers agree that the smart city is a multi-faceted concept, and various researchers have proposed sets of smart city dimensions or frameworks. For example, Nam and Pardo $(2011,187)$ identify a set of strategic principles aligned to three key dimensions (technology, people, and institutions) of the smart city. In a synthesis of the literature, Anthopolous et al. (2019) identify eight common dimensions in existing smart city models. They propose a unified smart city model comprising: smart city architecture, governance, planning and management, data and knowledge, energy, health, people and environment. Höjer and Wangel (2015) define the smart sustainable city as "a city that meets the needs of its present inhabitants without compromising the ability for other people or future generations to meet their needs, and thus, does not exceed local or planetary environmental limitations, and where this is supported by ICT" (p. 342).

It is also important to consider how to build the sustainability of the smart city as a phenomenon. Unless a smart city is sustainable as a working system, it cannot achieve its goals and objectives. This can be seen as a valid contemporary concern given the early stage of the smart city as a global phenomenon on the adoption curve, and the ambitious goals that smart cities are charged with. Studies indicate that smart cities (and therefore their leaders) face a number of challenges, barriers and critical success factors (Chourabi et al. 2012; Nam and Pardo 2011) in meeting their objectives. Nam and Pardo's synthesis (2011) highlights issues at technological, organisation, policy and context level: the need for efficient, effective management, improved interoperability within or across organisational boundaries, and to deal with risks such as organisational conflict, resistance to change, and misalignment between 
goals and projects. Technical risks include lack of knowledge, incompatibility, too much hope, and security issues; policy needs to be adapted support an enabling environment; and consideration must be given to contextual issues. Leaders play a key role in relationship to delivering "smart governance", one of six dimensions that are seen as necessary for the smart city (Giffinger and Gudrun 2010; Höjer and Wangel 2015; Anthopoulos and Reddick 2016a). This concept requires "transformation of local government to transparent, efficient and open to its citizens with the use of the ICT as well as the formulation of the appropriate smart city policies" (Anthopoulos and Reddick 2016a, 351).

Clearly the leaders of smart city leaders face significant challenges. Note only do smart cities aim for lofty goals, but they face public scrutiny, with indices such as the City in Motion Index (IESE Business School 2018) being used to generate global rankings. Further, the innovative nature of smart city initiatives are seen as requiring a different management approach to that of the traditional business as usual of the city (Van den Bergh and Viaene 2015). In the related context of e-government implementation, effective leadership is seen as critical in bringing about successful transformation (Elnaghi and Alshawi 2007). E-government has created a demand for leaders with cross-boundary skills, and egovernment leaders have been found to require competencies in setting new directions, transforming process and resource use, and using information strategically (Elnaghi and Alshawi 2007). However, there is a signficant lack of empirical research into leadership practice in the context of the smart city. An exception is work by Nicholds et al. (2017) that uses place leadership as a lens to examine coproduction of leadership across organisations, disciplines and professions. The authors suggest that leaders in this environment require more relational and technical leadership skills than are needed in traditional city management settings. Van den Berg and Viaene (2015) have identified a number of challenges that the smart city poses for city administrators. These include allocating the locus for leadership, establishing co-ordination mechanisms, managing IT-business alignment, shaping organisational culture, and going beyond the experimental phase. Our study follows this broad line of concern by investigating the nature of smart city leadership that is performed by those in the city administration, with a focus on moving beyond the early stage of smart city piloting and quick wins to embed the smart city transformation in local and municipal government.

It is beyond our scope to review the vast field of leadership theory. Dinh et al. (2014) identified 66 different leadership theory domains, while Dionne et al. (2014) identified 29 different leadership theories, models and approaches. Our focus is not on identifying the behaviours or styles of individual leaders, but rather on identifying the common leadership practices (whether individual, shared or distributed) that are undertaken by a range of individuals in the course of their work to deliver smart city programmes and embed the smart city in local government administrative processes. In this sense the study is more aligned with descriptive leadership theory (concerning how leaders actually act in practice) than normative leadership theories (that prescribe how leaders should act; well-known examples being transformative leadership, servant leadership, and authentic leadership). We note, however transformational leadership theory (Bass and Riggio 2006) which positions leaders as change agents who initiate and implement new directions within organisations, and work to institutionalise change by deconstructing old practices and establishing new ones based on innovative visions and ideas.

Leadership role typologies linked with diverse leadership practices have been categorised in many different ways in the literature. In a 1971 study, Henry Mintzberg found that managers perform "ten basic roles which fall into three groupings" (Mintzberg 1971, B-97). He called these interpersonal roles, information processing roles and decision-making roles. Further, Mintzberg argued that these three groups and 10 basic leadership roles can be used to categorise a manager's different functions. In a later study, Mintzberg (2009) derived a theory of management and confirmed the leadership roles he had found 40 years before. Some years later Kotter (2012) studied organisational change and found that change needs a guiding coalition where both leadership and management are represented. Based on many years of research in management teams at Henley Management College, Meredith Belbin (Belbin 2010, 2012) found three main roles, each with three sub-roles that are needed in a team. The first group of main roles are Action-oriented. The sub-roles are Shaper, Implementer and CompleterFinisher. The second group comprises people-oriented roles. Here the three sub-roles are Coordinator, Team Worker and resource Investigator. Finally, the third group called Thought-oriented roles, con- 
sists of Plant, Monitor-Evaluator and Specialist. Prior research has identified that effective leaders may exhibit a complex of behaviours, performing a portfolio of complementary roles (Denison et al. 1995, 527). For example, Quinn's model (1988) conceptualises the leader as playing roles of the innovator, broker, producer, director, coordinator, monitor, facilitator and mentor in different situations.

Finally, we note a four-part leadership typology used by Contractor et al. (2012), adapted from Carson and Teluk's (2007) analysis of convergence in prior leadership studies around the four role dimensions: the Navigator, Engineer, Social Integrator, and/or Liaison.

\section{$3 \quad$ Research method}

As the smart city is still a new phenomenon, our study was exploratory in nature. We set out to explore the practical work done by smart city leaders in driving and embedding change in the context of the smart sustainable city, focusing on how to move beyond the experimental (piloting or showcasing) stage. Our goal was not to study any specific leadership role, but rather to explore and understand barriers to embedding of the smart city phenomenon, and emergent practices that leaders are using to embed the smart city and increase its sustainability. It is unlikely that any one civic leadership role could result in effective smart city leadership: smart city projects are complex and leadership research evidences a shift away from a focus on the individual leader towards a view of leadership in practice as being distributed, collective, or pluralised leadership (White et al. 2016). We therefore conducted exploratory interviews with individuals employed by cities whose roles involved a strong focus on smart city leadership, aiming to capture complementary perspectives on smart city leadership, and the nature of challenges involved. We included participants from a range of global regions and city sizes/densities, with the goal of identifying common themes and concerns. To identify potential candidates, we combined an online search of public Linked In profiles (looking for the term "smart city" in job titles) in tandem with online searches of smart city programmes. We identified leaders of smart city programmes that were orientated towards generating value for citizens using IT and data, and were at least three years into the smart city programme. Participants were approached by email and invited to participate. Seven of these were interviewed. We interviewed two CIOs charged with leading smart city initiatives, three smart city programme managers, a city innovation lead, and one independent consultant who had extensive experience working with smart cities as a smart city adviser and private sector partner. We included the smart city adviser in order to gain understanding of issues and trends from the perspective of smart city partners, but also in order to access a perspective on broader trends across smart cities. (As the smart city is such a new phenomenon, the civic leaders we interviewed had had experience in leading in only one setting). Two participants were from cities in the European Union, two were from different states in USA, and three were from Oceania (Asia/Pacific). Three were female and three were male. Table 1 below shows the participant and city breakdown.

\begin{tabular}{|l|l|l|l|l|}
\hline$\#$ & Region & Pseudonym & Role & City Classification (using OECD definitions) \\
\hline 1 & EU & Nina (F) & CIO & Large town (15,000-20,000) \\
\hline 2 & EU & Carl (M) & Programme manager & $\begin{array}{l}\text { Metropolitan area (500,000 - 1.5 M) contiguous } \\
\text { within a large metropolitan area (2.7 M) }\end{array}$ \\
\hline 3. & USA & Kris (M) & CIO & $\begin{array}{l}\text { Small city/urban area (50-200,000) within a metro- } \\
\text { politan area of over 1.5M }\end{array}$ \\
\hline 4. & USA & Fiona (F) & Programme manager & $\begin{array}{l}\text { Metropolitan area (500,000 - 1.5 M) contiguous } \\
\text { with large metropolitan area (2.5 M) }\end{array}$ \\
\hline 5. & Oceania & Valerie (F) & Programme Manager & $\begin{array}{l}\text { City with medium sized urban area population 200, } \\
\text { 000- 500, 000 }\end{array}$ \\
\hline 6. & Oceania & Tony (M) & Innovation lead & Medium sized urban area (200,000-500,000) \\
\hline 7. & Oceania & Luke (M) & Consultant & Various, includes large metropolitan areas (1.5 M+) \\
\hline
\end{tabular}


Following the interpretivist tradition (Walsham 1995; Smith 2006), we sought to understand the smart city leadership experiences of participants from their personal perspectives. We conducted semi structured interviews lasting between 60-90 minutes, asking about their leadership experience, what was distinctive about smart city leadership, challenges to the sustaining their city's smart city vision, and the work they did to address barriers and help achieve benefits, such as using smart city data to generate insights and decisions. Interviews $\# 1, \# 2$ and $\# 6$ were conducted face-to-face whereas interviews \#3 - \#5 and \#7 were conducted in a tele-conference (Zoom or Skype).

In the course of interviews, we asked the interviewees to share stories about specific events. The recorded interviews were transcribed and sent back to participants for checking. We imported these transcripts into the qualitative analysis programme NVivo and iteratively coded them. Using analytic induction (Miles et al. 2014) combined with grounded theory coding techniques (Corbin et al. 2014) we firstly created 29 initial codes relating to barriers and 42 codes for leadership activities. We then created codes for families of barriers and merged the codes into larger categories identifying the main types of barriers reported below. In the second round of coding, in order to determine suitable higher-level categories for leadership practice, we re-engaged with the literature in a reflexive analytical process. Our data clearly showed that the smart city leaders were simultaneously involved in playing multiple role, or role dimensions. The final set of five leadership role dimensions that are outlined in the findings draws on several of the leadership role typologies reported above.

In the discussion we draw on the theoretical lens of institutional logics (DiMaggio 1988; Thornton and Ocasio 1999, 2008; Busch et al. 2018; Durand and Thornton 2018; Thornton et al. 2012) to further consider the nature of the challenges faced, and roles performed by, smart city leaders. Institutional logics are "socially constructed historical patterns of cultural symbols and material practices, assumptions, values, and beliefs by which individuals produce and reproduce their material subsistence, organize time and space, and provide meaning to their daily activity" (Thornton and Ocasio 1999, 804). The institutional logics approach highlights how individual and organisational behaviour is located in a social context and explains the social mechanisms that influence these behaviours. (Thornton and Ocasio 2008, 122). When competing logics co-exist within an institution, the resulting institutional complexity make the job of individual actors difficult (Busch et al. 2018, 549). Prior work has highlighted how public service provision is bound up with the competing and co-existing institutional logics of state-professionalism and market-managerialism (Busch et al. 2018; Meyer et al. 2014).

\section{$4 \quad$ Findings}

Our coding and analysis identified six key barriers to smart city sustainability and five distinct faces, or role dimensions, of smart city transformational leadership. We report on these in turn. In the discussion, we draw on the theory of institutional logic to interpret our findings and their significance.

\subsection{Barriers to sustainability}

Six key barriers to the sustainable smart city transformation were identified: (a) lack of scalability arising from a focus on showcasing of quick wins, (b) misalignment of municipal government structures, processes and reward systems with the integrative approach of smart city initiatives, (c) legal, regulatory and security challenges, (d) lack of an innovation culture in city administration, (f) caution and risk aversion surrounding advances in data use, and (e) gaps in capability and knowledge.

\subsubsection{Lack of scalability arising from a focus on showcasing quick wins}

The desire for quick wins during the early stages of smart city development had resulted in some outcomes that were seen as unsustainable: In several cases, participants reported that the data generated by pilot projects was held in provider clouds and delivered to cities but was not integrated with city data. This was seen as limiting scalability, preventing integration, and preventing capability development within cities' IT and business units. As Nina explained: 
"We've been in a long phase now where [we] have been working with small pilot projects and they've been focused on making showcases, making it possible to show this is a smart thing to do. So, we've been working with [a] provider that has the whole ecosystem of data themselves. They split up the centres, they get the data into their own cloud somewhere, and maybe show them in an app or on the web or something. But it's an ecosystem that lives parallel to the municipality... It doesn't really grow the organisation and it's often very difficult to scale."

\subsubsection{Misalignment of municipal structures and processes with smart city needs}

Participants outlined a range of aspects of city business as usual being misaligned with the embedding and scaling up smart city initiatives. Key amongst these barriers were the budgeting system and the allocation of benefits to siloed business divisions that had been formed in an era predating integrated services. These things created powerful disincentives, making it difficult for leaders who were charged with 'flying the airplane while building it (Fiona). Carl explained that:

"The municipality isn't organised to facilitate innovation, and definitely not organised to facilitate smart cities .. You don't have a light post anymore, you have a charging station, you have camera points, you have $5 G$ on camera point, and you have light, because that is smart. You have one object in public space that can have different functions. However .. we have a department that's responsible for public safety. If one [department] is responsible for light, if one is responsible for electric charging for cars, and those are different organisations, when you want to make a decision on an object in public space which is integral, nobody owns it because there's no owner for integration functions."

For example, one smart city was considering installing food grinders to reduce waste. Under the current system, this would require the housing department to bear the costs of installing grinders, while the benefit would fall to the waste management department. In this siloed environment, Fiona explained, leaders constantly face the challenge of "how to add value to what we're doing without slowing down the project." Further, even within divisions, there may be no incentive for efficiency. Carl noted that, "In general when we talk about smart cities, you're talking about your city services and [these services] don't compete against the market, so there's no natural drive to improve. There's no adapt or die. It's just you know, you get your money, if you're not more efficient. But if you are efficient, you don't want to do it because you're going lose your budget, so there's no incentive to be better at what you're doing". For smart city leaders, the above challenges created a constant imperative "to figure out how to add value to what we're doing without slowing down the project" (Nina).

\subsubsection{Lack of an innovation culture in city administration}

Linked with the above challenges, participants reported the barrier of organisational culture that was risk averse and resistant to innovation. Luke (the consultant) noted that, "public servants typically don't want to be seen to make decisions. They'd rather a consultant make the recommendation and they'd sign off on a recommendation perhaps, or [and then they can say] 'no it's the consultant."' As Carl explained, the impact of culture as a barrier is significant:

"At the end of the day technology will work, it will function. ... if there's enough societal use for something, you will find the money.... But it's the culture that is by far the most difficult to create. And that's the thing everybody underestimates... Everybody starts with the problem, you [aim to] solve a problem. But we never view our organisation as a problem and it's almost as difficult to tackle as translating a challenge to technology solution" (Carl).

\subsubsection{Legal, regulatory and security challenges}

In order to gain quick wins, pilot projects had typically benefitted from being ringfenced as proof of concepts that were exempted from business-as-usual policy requirements. Moving smart city initiatives beyond piloting and scaling up was seen as involving diverse legal, regulatory, security and privacy challenges which were complex and potentially expensive to work through. Kris noted that, " $A$ lot of the smart city technology collects information now, and while it certainly can be largely benign, 
there's the perception potentially that you're collecting information, personal information and using it for nefarious means or reasons". Legislation was a barrier even if smart city innovations offered potential to better protect citizen privacy. Tony described how a pilot using automated cameras and machine learning algorithms to monitor citizen safety had potential to protect citizen privacy more effectively than the use of volunteers, yet scaling this up would require a major change to legislation.

\subsubsection{Caution and risk aversion surrounding data use}

The smart sustainable city concept is strongly associated with rhetoric about the use of data derived from sensors and the IoT to drive city and citizen-level improvements. However, a number of those interviewed revealed that their cities took a piecemeal approach to data use, were uncertain about how to move forward with data use, and had caution surrounding the application of data relating to citizens into service-related decisions. This can be seen as being linked to the previous barrier. Carl noted that, "we have loads of data flowing in, but the question for [this city and] all municipalities is what do you actually do with the data?". Although his city was applying world-edge automated decision models drawing on data in relationship to transport and water management, the majority of gathered data was not used to drive decisions, and was in demand by divisions of the municipality, even if there was an identified revenue or savings opportunity. Further, Carl saw politicians as a key barrier to the expansion of the use of data driven decision-making. He noted that, "Politics are about emotion... you can analyse everything, but for politicians it wouldn't be beneficial if everything would be transparent based on our data, because then they won't have a function anymore".

\subsubsection{Gaps in capability and knowledge}

Smart city programmes had created a high demand for new knowledge and exposed capability and knowledge gaps, notably relating to technology decisions, integration, and integration of data from city WANs with municipal data sets. On the part of leaders, lack of knowledge was not seen as a disincentive, but rather as a stimulating aspect of the change environment. Nonetheless, this issue led large time demands on leaders, and had exposed a gap between the capabilities and understandings of municipal governments and external providers and partners. This was more of an issue for smaller cities, where resources to develop new knowledge were constrained. Nina noted that, "We're all looking for somebody bigger than us to learn from... You have to spend a lot of time in meetings ...And I've been in some meetings where it seems like everybody... want[s] to lean on somebody else and if there's nobody who really stands there to lean on then everybody's just leaning."

Perhaps the most significant barrier faced by leaders was that the norms and frames of reference held by colleagues responsible for delivery of city services often made it hard for these people to see smart city technologies as an enabler of service delivery. This created a demand to be knowledgeable about city services. Nina noted, "The people who actually know something about the core service that we deliver do not know anything about the technical possibilities, and I don't really know much about what they really do out there with the citizens. So, bridging those things is always [an issue]".

\subsection{Five faces of smart city leadership: role dimensions and practices}

Our analysis of the data revealed that smart city leadership involved five distinct faces, or role dimensions, with associated enabling practices, so as to foster and embed change that contributed to smart city sustainability. Although these role dimensions were not equally performed by any of the individual participants (all reported some distribution of smart city leadership within their cities), all identified activities in each category as being important part of their city's leadership approach. All the participants were active in performing some aspects of each role dimension. The five faces were: the navigator (establishing, maintaining and defending a clear vision and direction, while enacting strategic moves to achieve specific ends that fostered progress); the engineer (structuring the smart city collective and tasks); the storyteller (telling stories and customising information to make it relevant to specific groups): the learner / knowledge builder (learning and modelling learning); and the relationship builder (building and enriching internal and external relationships). We outline each role below. 
In the discussion, we consider the significance of these roles, and the barriers they address, drawing on institutional logics theory.

\subsubsection{The Navigator}

The Navigator role was about providing a clear sense of purpose and direction to help guide and support those implementing the smart city programme, while enacting diverse strategic moves to move ahead, stay on track, achieve timely outcomes, and bring resistant parties on board with the smart city journey. CIOs and programme managers placed a key emphasis on this aspect of leadership work. It involved establishing, maintaining and defending the smart city vision, bringing others on the journey by helping them develop aligned visions and goals, and designing moves such as work-arounds to address barriers to progress. Other activities in this category were: spearheading the vision, soliciting policy owners to anchor initiatives and make them scalable, engaging in temporary work-arounds, demonstrating value so as to encourage other to come on board, agreeing to shoulder risk as a trade-off for buy-in, piggybacking on existing political decisions, selecting strategic wars, agreeing on exit strategies with vendors up front, strategizing to avoid gathering individually identifiable data, and embedding smart city initiatives with the city business plan.

The leaders interviewed acknowledged that they played key leadership roles in smart cities but also emphasised that distributed leadership and ownership was required across the organisation for the smart city to become embedded in the city's business as usual. It was therefore an important part of their job to find ways to bring others on board and foster ownership. This included strategic moves in addition to relationship building (e.g., agreeing for the smart city programme to shoulder risk so as to encourage buy-in). There was a strong component of change management involved:

"You're trying to bring people to change their notions about how they've always done things... [change] is a strong component and it's not really a stated component of the role. So, if you think about what I'm measured on it is really creating output that brings innovation into the city. However, that output will never be made operational unless I can manage the change" (Valerie).

Leaders also reported on personal characteristics and values that were conductive to the navigator role: "[It requires] an enormous amount of drive, you have to be an absolute advocate in what you believe, because basically, you have to do a lot of pulling, you have to pull a lot in the organisation. You have to drag people along. ... It helps if you can create a vision and inspire people to move" (Carl).

\subsubsection{The Engineer}

The Engineer role involved structuring the smart city collective and tasks, and coordinating the work of diverse members to meet the smart city goals. Fiona stated, "My job is, day to day, it's kind of ensuring that the pieces and parts all keep on working toward the same outcome" (Fiona).

In many projects and programmes the engineer will have the title of project manager. The engineer is responsible for designing optimal delivery paths, brokering supply and demand and orchestrating the deal(s) with suppliers and contractors.

In the process of delivering the smart city the engineer needs to improvise solutions and balance innovation with reuse. Finally, the engineer coordinates internal and external resources and is responsible for combining data to make progress visible, "We put together a program metrics and set up a dashboard, I'll say that they weren't really utilised by the executives. And then I realised that what I needed ...was to have more ties to existing programs that pull data in terms of spend and invoices" (Fiona).

\subsubsection{The Storyteller}

The Storyteller role is about creating a common understanding for the vision of the smart sustainable city. To do that the storyteller tells stories about the future in the sustainable smart city, "I think of myself as kind of a storyteller, or translator of the different technical community executives, the technical teams to other technical teams that are outside of our team outside of the city. I'm communicating that to the executives, to other organisations, partner organisations, other cities" (Fiona). 
The storyteller is also responsible for customising stories for the audience - translating the story so to say, "I see it as my role to try and give her some idea of, "you could do this, you could do this, you can do this, you could do this". So, "What would fit into your picture of the ideal way forward for your area?", and so if I don't, so if we don't work together, we don't go anywhere. I can't do it alone. She can't do it alone" (Nina).

In addition, the storyteller role is about fostering structured and aligned thinking and support others in telling stories, "We let them present once a month. They can present their innovation. I have a copywriter who writes a little piece about people, infuse people so we promote it and we do it on different levels." (Carl). Finally, the storyteller role includes supporting the building of artefacts - so-called "pillars of support" to help promote smart city transformation.

\subsubsection{The Relationship Builder}

The Relationship Builder has contact with all the stakeholders; citizens, politicians, city employees, etc. The relationship builder builds networks with all the stakeholders and helps bring about ideas in the networks. Nina noted, "It's my job to try and open up perspectives and see new possibilities that would else not come to the table. And I think of course that's also very relation bound in a way. So, for the other heads that I work closely with, it's easier to bring about those thoughts...It's very important to have good relationships.

Relationship building helps to generate ideas for solutions that leaders can then undertake in the engineer role. For example, Tony reported on how his city had embarked on a "privacy by design approach" after consulting with the privacy commissioner. Frontline staff were trained and video analysis algorithms applied in such as way that the city could analyse begging patterns without gathering personally identifying information. This provided a practical means to address regulatory challenges.

The relationship builder also builds shared ownership and bring others on board. Kris noted that, "Smart city-related work is an all hands on deck type activity. So, it starts with having the leadership support right from the elected officials. Then you've got to make sure you're budgeting through the administrative services. Clearly IT needs to be on board. You need support from your legal department. A lot of the back office administrative functions have to be engaged. And then you think about something like the different departments, libraries. Well, our library department is one of the most sophisticated users of tech in the city and so they are pushing a whole range of smart city-related activities. And I look at public works or I look at our, even our police and fire [service], the degree to which they're using new technology for apprehending criminals or processing data, storing data."

Finally, the relationship builder creates and rewards internal champions, "I've tried to create champions on different levels, on product level, people that do something, we brand them as a champion, we put them on a pedestal. We let them present once a month" (Carl).

\subsubsection{The Learner / Knowledge builder}

The Learner/Knowledge builder is responsible for bringing in knowledge and learning from outside. He or she takes responsibility for own learning and will be 'leaning' on others who have expertise.

The learner/knowledge builder also engages with communities of practice, "There are innovators in various organisations around the country, in my city obviously a lot, but also around the country who you see as kindred spirits, and you network with those people, and those are the people that you tend to tack on to make things happen as well. Because they have a similar attitude, it's almost like you can speak shorthand with each other" (Valerie).

Furthermore, the learner/knowledge builder needs to creatively be challenging norms and prejudices to find and learn new solutions: "There are two organisations that I should be creating a lot of headaches for. First are the security people, cyber security and the second are the attorneys, the legal people. Because if I'm pushing on both of those, it means we're out of our comfort zone and we're doing something new, we're doing something that no one's done before, or has a little bit of uncertainty to it. It definitely has elevated risk. The attorneys ... they're really smart and they do their job exactly right, 
but it causes them headache, and I have to get creative with them and say, "Well, what if we do it this way or.." and sometimes you know, they'll help me. They'll say, "well, you know what... here's the way you can do it because the law or the ordinance allows this" (Kris).

The learner-knowledge builder role is also strongly proactive in identifying and addressing professional development needs of other staff. For example, Tony commented on how the increased use of data in relationship to building consents was changing the nature of early career work in urban planning, and how front-line staff needed to be dissuaded from gathering personally identifiable data, so as to reduce risk of privacy infringements. He noted that he was discussing how to respond to new professional knowledge needs with a company that had had a similar impact on the accounting profession.

\section{Discussion, Implications and Conclusion}

We draw on the theoretical lens of institutional logics (DiMaggio 1988; Thornton and Ocasio 1999, 2008; Busch et al. 2018; Durand and Thornton 2018; Thornton et al. 2012) to further consider the nature of the challenges faced, and the roles performed by, smart city leaders. Moves to embed smart city innovations in city business as usual can be seen as perpetuating and increasing the institutional complexity faced by leaders of change. The emergent logic of the smart city can be seen as based on a radically integrated view of city infrastructure, data, and benefits arising. It also places value on innovation and discovery, and views financial, social and environmental benefits as being delivered by rational responses to insights based on combining data from the smart city infrastructure with traditional data sources. This may entail iterative and agile revision of a city's operating procedures, policies, and resource allocation. In contrast, the traditional bureaucratic, state-professionalism logic of municipalities is based around managing equitable delivery of discrete service lines to citizens, ensuring department-level budgetary accountability, working within policies, and protecting future budget allocations. The fundamental challenges faced by smart city leaders and the nature of leadership work performed, can be seen as arising from this clash of logics.

For example, Carl outlined how a scanning car that issued parking tickets had identified clear patterns of parking infringements in the city. Despite this, decisions about where to send the car were still being made by the department concerned according to the traditional process, without taking account of the predictive value of the data gathered. The logic implied in the smart city view - that the car should be sent to 'optimal' ticketing locations (thus helping disincentivise car use while optimising city revenue) can be seen as conflicting with the logic of sending the car to locations selected on a democratic geographic coverage basis. The traditional car allocation system can be seen as based on a logic of state professionalism, in which work is executed according to policies and values such as fair and equal treatment of customers and impartiality (Busch et al. 2018). 1On the other hand, the smart city logic draws on market-managerialism, merging public interest with a strong emphasis on efficiency and performance (Busch et al. 2018). Similarly, the work of smart city leaders to embed the smart city approach can be seen as addressing clashes of logic in relationship to the incentivisation of savings, the allocation of benefits, attitudes about how to tackle privacy issues, and the role of policy as an enabling or constraining force. (For example, securing business and policy owners helps shore up smart city approach by trying it to structures linked with bureaucratic state-professional logic).

The smart city leaders in this study can be seen as entrepreneurial change agents working across the boundary of competing institutional logics of the city. Their leadership roles as engineer, navigator, and storyteller position them as institutional entrepreneurs, agents who work to create new, and modify old, institutions (Thornton and Ocasio 2008; DiMaggio 1988). Institutional entrepreneurs are known to use strategies such as storytelling and rhetorical strategies to "creatively manipulate social relationships by importing and exporting cultural symbols and practices from one institutional order to another" (Thornton and Ocasio 2008, p 115) - this work was strongly evident in the storyteller role. The findings also demonstrate that smart city leaders also play critical roles as boundary-spanners. Boundary spanners are actors who span different contexts while understanding and bridging the cultures and norms of each, thus facilitating knowledge transfer and change (Tushman and Scanlan 1981; Levina and Vaast 2005; Prusak and Cross 2002). In order to move beyond showcasing of smart city 
initiatives, smart city leaders need to be skilled boundary spanners of conflicting institutional logics. As boundary-spanners, the smart city leaders had to continually negotiate the boundaries of the different city logics, making strategic decisions about whether and how to respond to conflicts of logic. They decided which battles were worth engaging in, when to shoulder risk to gain buy-in, and how to invite buy-in by telling stories, translating benefits, creating social rewards for smart city champions, and demonstrating value of smart city projects. To improve the sustainability of promising smart city initiatives they had to draw on traditional (bureaucratic, state-professionalism) logic of the city by identifying business and policy owners for projects that would otherwise be unsustainable. However, they also had to work around traditional logic, so smart city gains were not lost (for example, Valerie used an outsourcing agreement until the relevant service division built an understanding of the benefits of using sensors, and changed their master outsourcing agreement. In the storyteller role, smart city leaders needed to work with new business owners to help them understand and appropriate smart city logic (such as the value to citizens of using data-informed insights when city processes are seen as adaptive). Table 2 illustrates the way in which the different faces of leadership were combined to help address two of the six barriers.

This study has contributed valuable insights into the nature of smart city leadership and demonstrates potential for the institutional logics to be used as a lens to help understand the nature of transformation that is based around the phenomenon of a smart city. From the perspective of institutional logics, the 'five faces' of smart city leadership take on a new light: The navigator establishes pathways and negotiates boundaries of logics, the engineer builds structures for change, the storyteller uses stories to span logics and persuade, the relationship builder helps to bring people towards the logic of the smart city, and the learner-knowledge-builder helps strengthen and embed the new logic. The study shows that it is vital for smart city leaders also need to be skilled boundary-spanners, capable of understanding the dominant logics of the municipality, in order to help embed smart city approaches in city business as usual. The traditional logics of municipalities are likely to co-exist for some considerable time with the emerging logic of smart city logics. However, managers should bear in mind that institutional logics can be embedded in organisational design (Thornton et al. 2012). Future work could investigate the role of organisational design in helping smart city transformation. It could also look more closely at distributed leadership of smart city transformations, and at leadership the alignment between leadership development approaches and performed role requirements.

\begin{tabular}{|l|l|}
\hline Barrier & Salient leadership roles with sample activities \\
\hline $\begin{array}{l}\text { Lack of scalability arising } \\
\text { from a focus on showcas- } \\
\text { ing quick wins }\end{array}$ & $\begin{array}{l}\text { Navigator: shape vendor agreements to ensure data is owned by, and accessible to, the } \\
\text { city for purposes of scalability } \\
\text { Engineer: orchestrate the integration and interoperability of smart city and city data } \\
\text { Relationship builder: identify policy and business owners and work with them to } \\
\text { overcome the scalability barrier } \\
\text { Learner/knowledge builder: do deep dives to understand scalability and data integra- } \\
\text { tion problems; explore how other cities have addressed these issues }\end{array}$ \\
\hline $\begin{array}{l}\text { Lack of an innovation } \\
\text { culture in city administra- } \\
\text { tion }\end{array}$ & $\begin{array}{l}\text { Navigator: seek out and reward owners of innovation } \\
\text { Storyteller: tell compelling stories to bring others on board and lower barriers to ac- } \\
\text { cepting smart city logic (e.g. failure is acceptable) } \\
\text { Relationship builder: foster co-ownership of smart city innovation } \\
\text { Learner/knowledge builder: encourage learning and foster an innovation mindset }\end{array}$ \\
\hline
\end{tabular}

Table 2. Two examples of role action in relation to barrier 1 and barrier 3

Prior research has identified that leaders may exhibit a complex set of behaviours, performing a portfolio of complementary roles (Contractor et al. 2012; Denison et al. 1995, 527; Johansen and PriesHeje 2007; Quinn 1988). This study supports these findings and identifies a complex and intertwined set of roles to be enacted on the part of smart city leaders. However, we are not suggesting that any one person should aim at performing all roles equally, the study should be seen as identifying a set of 
key leadership roles and practices that facilitate local government transformation through embedding smart city approaches, and highlighting the skilled work involved in achieving mutual accommodation between smart city logics and traditional municipal culture, processes and policies. Five distinct role dimensions, or faces, were found to contribute to smart city leadership. The diversity of these roles supports Belbin's discovery of the need for action-oriented, people-oriented and thought-oriented roles: the role of navigator can be seen as primarily action-oriented, the roles of engineer and learner/knowledge builder as being primarily thought-oriented, and the story-teller and relationship builder roles as being primarily people-oriented. However, it is notable that the five smart city leadership roles in this study all involved a significant people orientation, despite the technological orientation of smart cities. Our study supports the work of Nicholds et al. (2017) in finding that leaders in the smart city environment require strong relationship and technical leadership skills. The relational aspect of leadership was most strongly stressed as being important by participants and was particularly evident in the roles of storyteller and relationship builder. As for technical skills, the smart city leaders in our study stressed the importance of their work as engineers (co-ordinating and structuring the technical work, and building shared understanding) and learner/knowledge builders (pushing the boundaries of technical norms and suggesting new ways of doing things), rather than their technical skills per se. In other words, their technical background equipped them with the facility to work in boundary-spanning roles, acting as a bridge between different technical communities, and between technical and nontechnical communities. The nature of this boundary-spanning work was captured by one interviewee Fiona, who noted, "I think of myself as kind of a storyteller, or translator of the different technical community executives, the technical teams to other technical teams that are outside of our team outside of the city. I'm communicating that to the executives, to other organisations, partner organisations, other cities.... I think that [I have] that [ability], combined with a experiential knowledge of the technical component, and that's really hard to operationalise. And I'm always having to figure out what that middle ground is."

This study extends prior research into the barriers facing smart city administrators (e.g. Van den Berg and Viaene, 2015) by identifying the specific barriers facing smart city leaders. Of particular interest, given the emphasis of smart city logic on deriving value from data analytics, are the barriers of caution and risk aversion surrounding data use, legal and regulatory challenges, and capability gaps. The boundary-spanning relationship work performed with business owners and other stakeholders can be seen as critical to addressing these barriers, but required time and is difficult to scale up. The barriers of establishing co-ordination mechanisms (found by Van den Berg and Viaene, 2015) can be seen as being addressed by the leadership roles of navigator and engineer that were identified in this study.

Many digital transformations in the public sector happens at the local municipal level. This exploratory study investigated smart city leadership with a focus on how leaders enact smart city transformation in their day to day practice. We have derived a framework of six barriers to overcome and five leadership roles that need to be enacted to transform the city of today to a future sustainable smart city.

At a practical level, the utility of our findings lies partly in using the six barriers to assess the readiness of a given city to undertake a project or program in order to realise a future sustainable smart city. The barriers we have identified are relevant to digital transformation of the public sector, and it should be of value for municipal managers to consider and work to address these barriers. Thus, it is highly relevant for city managers to discuss the barriers identified and consider how to overcome these barriers; identifying coping strategies. For example, barrier one about the lack of scalability is an important barrier to consider before engaging with the very first supplier or contractor about a showcasing project. Money and effort will be wasted if the showcasing project doesn't scale. If it is thought about proactively, the city may be able to set up architectural requirements that allows the results of the first smaller project to scale. Other examples worth considering proactively are security and privacy challenges. Information systems security cannot be "glued on" to a project at the end. Further, privacy risk will be increased if personally identifying data is gathered in the course of smart city data harvesting. It is therefore valuable and innovative for cities to proactively avoid gathering such data, as was mentioned as a strategy by one of the leaders interviewed. 


\section{References}

Albino, V., U. Berardi, and R. M. Dangelico. 2015. Smart cities: Definitions, dimensions, performance, and initiatives. Journal of Urban Technology 22 (1), 3-21.

Anthopoulos, L., M. Janssen, and V. Weerakkody. 2019. A unified smart city model (USCM) for smart city conceptualization and benchmarking. In Smart Cities and Smart Spaces: Concepts, Methodologies, Tools, and Applications USA: IGI Global, 247-264.

Anthopoulos, L. G. 2017. Understanding Smart Cities: A Tool for Smart Government Or an Industrial Trick? Vol. 22. Basel: Springer

Anthopoulos, L. G., and C. G. Reddick. 2016a. Smart City and Smart Government: Synonymous or Complementary? Paper read at Proceedings of the 25th International Conference Companion on World Wide Web April 11-15, at Montreal.

Anthopoulos, L. G., and C. G. Reddick. 2016b. Understanding electronic government research and smart city: A framework and empirical evidence. Information Polity 21 (1),99-117.

Bass, B. M., and R. E. Riggio. 2006. Transformational leadership. : Psychology Press.

Belbin, R. M. 2010. Management teams: Routledge.

Belbin, R. M. 2012. Team roles at work: Routledge.

Bibri, S. E., and J. Krogstie. 2017. Smart sustainable cities of the future: An extensive interdisciplinary literature review. Sustainable Cities and Society 31,183-212.

Brauer, B., M. Eisel, and L. M. Kolbe. 2015. The State of the Art in Smart City Research-A Literature Analysis on Green IS Solutions to Foster Environmental Sustainability. PACIS 2015 Proceedings. 74.

Busch, P. A., H. Z. Henriksen, and Ø. Sæbø. 2018. Opportunities and challenges of digitized discretionary practices: a public service worker perspective. Government Information Quarterly 35, 547-556.

Chourabi, H., N. Taewoo, S. Walker, J. R. Gil-Garcia, S. Mellouli, K. Nahon, T. A. Pardo, and H. J. Scholl. 2012b. Understanding Smart Cities: An Integrative Framework. 2012 45th Hawaii International Conference on System Sciences (HICSS), 2289-2297.

Cocchia, A. 2014. Smart and digital city: A systematic literature review. In R. P. Dameri \& C. Rosenthal-Sabroux (Eds.), Smart City, progress in IS (pp. 13-43). Berlin: Springer.

Contractor, N. S., L. A. DeChurch, J. Carson, D. R. Carter, and B. Keegan. 2012. The topology of collective leadership. . The Leadership Quarterly 23 (6), 994-1011.

Corbin, J., A. Strauss, and A. L. Strauss. 2014. Basics of qualitative research: Sage.

Denison, D. R., R. Hooijberg, and R. E. Quinn. 1995. Paradox and performance: Toward a theory of behavioral complexity in managerial leadership. Organization Science 6 (5), 524-540.

DiMaggio, P. J. 1988. Interest and agency in institutional theory. In Institutional Patterns and Organizations: Culture and Environment. Cambridge, MA: Ballinger. 3-21.

Dinh, J. E., R. G. Lord, W. L. Gardner, R. C. Liden, and J. Hu. 2014. Leadership theory and research in the new millennium: Current theoretical trends and changing perspectives. The Leadership Quarterly 25 (1), 36-62.

Dionne, S. D., A. Gupta, K. L. Sotak, K. A. Shirreffs, A. Serban, C. Hao, D. H. Kim, and F. J. Yammarino. 2014. A 25-year perspective on levels of analysis in leadership research. The Leadership Quarterly 25 (1), 6-35.

Durand, R., and P. Thornton. 2018. Categorizing Institutional Logics, Institutionalizing Categories: A Review of Two Literatures. Academy of Management Annals, (ja). 12 (2).

Elnaghi, M., and S. Alshawi. 2007. A Leadership Model for e-Government Transformation. Proceedings of European and Mediterranean Conference on Information Systems 2007 (EMCIS2007), June 24-26, 2007. 48.

Giffinger, R., and H. Gudrun. 2010. Smart Cities Ranking- An Effective Instrument for the Positioning of Cities? ACE Architecture, City and Environment 4 (12), 7-25.

Höjer, M., and J. Wangel. 2015. Smart sustainable cities: definition and challenges. In ICT innovations for sustainability. Berlin: Springer-verlag, 333-349. 
Hollands, R. G. 2008. Will the real smart city please stand up? Intelligent, progressive or entrepreneurial? City 12 (3), 303-320.

IESE Business School. 2019. Cities in Motion Index 2018 [cited 30 October 2019]. Available from https://www.iese.edu/en/faculty-research/research-centers/cgs/cities-motionstrategies/index.html.

Johansen, J., \& Pries-Heje, J. 2007. Success with improvement - requires the right roles to be enacted - in symbiosis. Software process: improvement and practice, 12(6), 529-539.

Khan, Z., A. Anjum, K. Soomro, and M. A. Tahir. 2015. Towards cloud based big data analytics for smart future cities. Journal of Cloud Computing. 4 (1),2.

Kotter, J. P. 2012. Leading change: Harvard Business Press.

Levina, N., and E. Vaast. 2005. The emergence of boundary spanning competence in practice: Implications for implementation and use of information systems. MIS Quarterly 29 (2), 335363.

Lin, C. J. 2018. Five Chinese smart cities leading the way. GovInsider. July $10^{\text {th }}, 2018$.

Meyer, R. E., I. Egger-Peitler, M. A. Höllerer, and G. Hammerschmid. 2014. Of bureaucrats and passionate public managers: Institutional logics, executive identities, and public service motivation. Public Administration 92 (4), 861-885.

Miles, M. B., A. M. Huberman, and J. Saldana. 2014. Qualitative data analysis: Sage.

Mintzberg, H. 1971. Managerial work: Analysis from observation. Management science 18 (2), B-97B-110.

Mintzberg. H. 2009. Managing: Berrett-Koehler Publishers.

Nam, T., and T. Pardo. 2011. Conceptualizing smart city with dimensions of technology, people, and institutions, 282-291. In Proceedings of the 12th annual international digital government research conference: digital government innovation in challenging times (pp. 282-291). ACM.

Nicholds, A., J. Gibney, C. Mabey, and D. Hart. 2017. Making sense of variety in place leadership: The case of England's smart cities. Regional studies 51 (2), 249-259.

Panetta, K. 2017. Smart Cities Look to the Future. Gartner. March $27^{\text {th }}$. Avaiable from https://www.gartner.com/smarterwithgartner/smart-cities-look-to-the-future/

Prusak, L., and R. Cross. 2002. The people who make organizations go-or stop. Harvard Business Review 80 (6),104-112.

Quinn, R. E. 1988. Beyond rational management: Mastering the paradoxes and competing demands of high performance: Jossey-Bass.

Reuters. 2018. Global Smart cities Market Size and Trends - Industry Analysis by Key Developments, Players, CAGR Growth Projection to 2023. March 192018.

Smith, M. L. 2006. Overcoming theory-practice inconsistencies: Critical realism and information systems research. Information and organization 16 (3):191-211.

Thornton, P., and W. Ocasio. 1999. Institutional Logics and the Historical Contingency of Power in Organizations: Executive Succession in the Higher Education Publishing Industry, 19581990. American Journal of Sociology 105 (3):801-843.

Thornton, P., and W. Ocasio. 2008. Institutional logics. In Greenwood, R., Oliver, C., Sahlin, K. Suddaby, R. (eds.). The SAGE handbook of organizational institutionalism. 840, 99-128. SAGE

Thornton, P., W. Ocasio, and M. Loundsbury. 2012. The Institutional Logics Perspective: A New Approach to Culture, Structure, and Process. New York: Oxford University Press.

Tushman, M., and T. Scanlan. 1981. Boundary spanning individuals: Their role in information transfer and their antecedents. . Academy of Management Journal 24 (2), 289-305.

United Nations Development Programme. Sustainable Development Goals. Goal 11: Sustainable cities and communities 2017. Available from

http://www.undp.org/content/undp/en/home/sustainable-development-goals/goal-11sustainable-cities-and-communities.html.

Van den Bergh, J., and S. Viaene. 2015. Key challenges for the smart city: Turning ambition into reality. Proceedings of 48th Hawaii International Conference on System Sciences (HICSS). 2385-2394. IEEE. 
Walsham, G. 1995. The emergence of interpretivism in IS research. Information Systems Research 6 (4), 376-394.

White, L., G. Currie, and A. Lockett. 2016. Pluralized leadership in complex organizations: Exploring the cross network effects between formal and informal leadership relations. The Leadership Quarterly 27 (2), 280-297. 